\title{
$5-2012$
}

\section{Introducing NOB-NOBs: nitrogen-oxygen-boron cycles with potential high-energy properties}

\author{
Aloysus K. Lawong \\ Cleveland State University \\ David W. Ball \\ Cleveland State University, d.ball@csuohio.edu
}

Follow this and additional works at: https://engagedscholarship.csuohio.edu/scichem_facpub

Part of the Physical Chemistry Commons

How does access to this work benefit you? Let us know!

Publisher's Statement

The final publication is available at Springer via http://dx.doi.org/10.1007/s00894-011-1203-4

\section{Recommended Citation}

Lawong, A. K.; Ball, D. W. Introducing NOB-NOBs: nitrogen-oxygen-boron cycles with potential high-energy properties. Journal of Molecular Modeling 2012, 18, 1723-1728.

This Article is brought to you for free and open access by the Chemistry Department at EngagedScholarship@CSU. It has been accepted for inclusion in Chemistry Faculty Publications by an authorized administrator of EngagedScholarship@CSU. For more information, please contact library.es@csuohio.edu. 


\title{
Introducing NOB-NOBs: nitrogen-oxygen-boron cycles with potential high-energy properties
}

\author{
Aloysus K. Lawong • David W. Ball
}

\begin{abstract}
As a follow-up on a study of a family of boronoxygen-nitrogen compounds composed of two datively bonded $\mathrm{B}-\mathrm{O}-\mathrm{N}$ backbones, we investigate a similar series of compounds that have similar fragments but are covalently bonded. B3LYP/6-31G(d,p) quantum mechanical calculations have been performed to determine the minimum-energy geometries, vibrational frequencies, and thermochemical properties of the parent compound and a series of nitro-substituted derivatives. Our results indicate that some of the derivatives have at least appropriate thermodynamics for possible high-energy materials, in some cases being favorable over similar dimeric compounds with coordinate covalent $\mathrm{B}-\mathrm{N}$ bonds.
\end{abstract}

Keywords NOB-NOB compounds · B3LYP calculations . High-energy materials

\section{Introduction}

In 1963, Kuhn and Inatome [1] published a report on an airstable boron-oxygen-nitrogen molecule that they determined was composed of two B-O-N molecules in the form of a six-membered ring. They later presented evidence, in the form of measured dipole moments, that the ring existed as a chair conformer [2]. Because experimental evidence suggested that the nitrogen atom in the $\mathrm{B}-\mathrm{O}-\mathrm{N}$ monomer made a coordinate covalent bond with the boron atom of the other monomer, Kuhn et al. referred to these molecules as "BONBON" species. Their derivatives had several $n$-butyl groups bonded to either the boron atom or the nitrogen atom (or

A. K. Lawong • D. W. Ball $(\bowtie)$

Department of Chemistry, Cleveland State University,

2121 Euclid Avenue,

Cleveland, OH 44115, USA

e-mail: d.ball@csuohio.edu both) in the ring. Recently, we (Lawong AK, Ball DW, 2011, manuscript in preparation) performed computational chemical analyses of the parent BON-BON molecule (the moniker of which we are choosing to give in all capitals, unlike Kuhn et al. [1, 2], to emphasize the atomic constitution of the sixmembered ring) and a variety of nitro-substituted BON-BON molecules in order to study their potential as new highenergy (HE) materials. The parent BON-BON molecule, cyclo- $\mathrm{BH}_{2} \mathrm{ONH}_{2} \mathrm{BH}_{2} \mathrm{ONH}_{2}$, is shown in Fig. 1 (Lawong AK, Ball DW, 2011, manuscript in preparation). Because both the $\mathrm{B}$ and $\mathrm{N}$ atoms are tetracoordinated, the molecule adopts a cyclohexane-like central ring structure.

In the course of our study, we realized that there is another way to link two B-O-N moieties: using actual covalent bonds between the $\mathrm{B}$ and $\mathrm{N}$ atoms between the two monomers, rather than coordinate covalent bonds. That is, a nitrogen atom on one $\mathrm{B}-\mathrm{O}-\mathrm{N}$ fragment would covalently bond with the boron atom on a second $\mathrm{B}-\mathrm{O}-\mathrm{N}$ fragment, with a similar covalent bond occurring between the other ends of the fragments. To differentiate this bonding arrangement from that found in BON-BON molecules, we propose the name "NOB-NOB" in reference to the covalently bonded six-membered ring. In this work, as a follow-up to our BON-BON study, we present a computational chemical study of the structures and properties (including the thermochemical properties) of the parent NOB-NOB molecule and nitro derivatives of NOB-NOB.

\section{Computational details}

All calculations were performed using the Gaussian 09 computational chemistry program [3] on an IBM cluster 1350 supercomputer at the Ohio Supercomputer Center in Columbus, Ohio. We used the density functional theoretical method, as defined by combining Becke's three-parameter exchange functional with the correlation functional of Lee, 


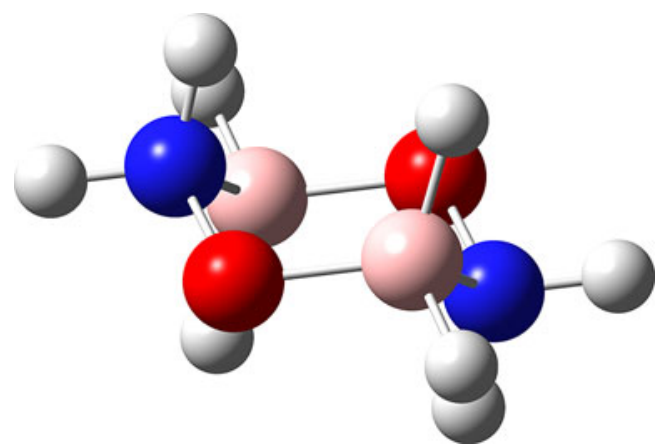

Fig. 1 The general structure of BON-BON-type six-membered rings. Because of the tetracoordinated $\mathrm{B}$ and $\mathrm{N}$ atoms, the ring adopts a cyclohexane-type structure, in this case the chair conformer. (From Lawong AK, Ball DW, 2011, manuscript in preparation)

Yang, and Parr (abbreviated to B3LYP in the Gaussian program) [4, 5], along with the standard Gaussian basis set labeled $6-31 G(d, p)[6]$. Minimum-energy geometries of the NOB-NOB molecules were determined using default settings, and vibrational frequency calculations were performed to verify that a minimum-energy geometry was found. Once the proper structure of the NOB-NOB molecule was established, the enthalpy of formation was determined by calculating the enthalpy change for the molecule formed from its gaseous elements, and then corrected for the enthalpy of formation of gas-phase boron. For example, the reaction for the parent molecule was

$$
\begin{array}{r}
2 \mathrm{H}_{2}(\mathrm{~g})+\mathrm{O}_{2}(\mathrm{~g})+\mathrm{N}_{2}(\mathrm{~g})+2 \mathrm{~B}(\mathrm{~g}) \\
\rightarrow \text { cyclo }-\mathrm{NHOBHNHOBH}(\mathrm{g}) .
\end{array}
$$

The energy change associated with this reaction was determined from the calculations and then corrected for the formation of two moles of $\mathrm{B}(\mathrm{g})$ :

$2[\mathrm{~B}(\mathrm{~s}) \rightarrow \mathrm{B}(\mathrm{g})] \quad \Delta \mathrm{H}=2\left[565.0 \mathrm{~kJ} \mathrm{~mol}^{-1}\right]$.

The enthalpy of formation for $\mathrm{B}(\mathrm{g})$ was taken from the NIST Chemistry Webbook website [7]. Once corrected for the formation of $\mathrm{B}(\mathrm{g})$, the energy represents the enthalpy of formation of the NOB-NOB molecule. After this, enthalpies of decomposition and/or combustion can be determined using standard balanced reactions, assuming that the products are $\mathrm{B}_{2} \mathrm{O}_{3}(\mathrm{~s}), \mathrm{H}_{2} \mathrm{O}(\mathscr{C})$, and $\mathrm{N}_{2}(\mathrm{~g})$. When necessary, $\mathrm{O}_{2}(\mathrm{~g})$ is added as a reactant for the complete oxidation of $\mathrm{B}$ and $\mathrm{H}$ in the molecules.

\section{Results and discussion}

The non-nitrated NOB-NOB compound has the formula (cyclo-)NHOBHNHOBH. There are nine nitro-NOB-NOB compounds: two nitro-NOB-NOB isomers, four dinitro-
NOB-NOB isomers, two trinitro-NOB-NOB isomers, and one tetranitro-NOB-NOB molecule. Thus, here we are reporting on a total of ten NOB-NOB compounds. For much of the presentation that follows, we will focus on the non-nitrated NOB-NOB molecule (referred to as the "parent NOB-NOB") and the tetranitro-NOB-NOB molecule, (cyclo)- $\mathrm{N}\left(\mathrm{NO}_{2}\right) \mathrm{OB}\left(\mathrm{NO}_{2}\right) \mathrm{N}\left(\mathrm{NO}_{2}\right) \mathrm{OB}\left(\mathrm{NO}_{2}\right)$. The less nitrated molecules have properties intermediate between the two extremes, and (except for their thermodynamics) this will be assumed unless there is something noteworthy about a particular nitro-NOB-NOB. Readers interested in learning more about the partially nitrated NOB-NOB compounds can contact the corresponding author.

Figure 2 shows the optimized geometries of the parent NOB-NOB compound and tetranitro-NOB-NOB, while Table 1 lists some representative bonding parameters of these two molecules. The structure of the parent NOB-NOB molecule should be compared to that of the parent BONBON molecule, shown in Fig. 1 (Lawong AK, Ball DW, 2011, manuscript in preparation): the parent NOB-NOB optimizes as a flat molecule, suggesting that the nitrogen atoms have strong $s p^{2}$ character, as opposed to the cyclohexane-like ring adopted by the BON-BON derivatives. As if to belie this, however, the bond angle that the $\mathrm{N}-\mathrm{H}$ bond makes with the oxygen atom in the ring is close to the expected near-tetrahedral angle: $108.3^{\circ}$ rather than the ideal $120^{\circ}$. This is likely due to an intramolecular interaction between the electropositive $\mathrm{H}$ atom and the electronegative $\mathrm{O}$ atom. On the other hand, the $\mathrm{B}-\mathrm{H}$ bond is oriented almost exactly $120^{\circ}$ (actually slightly less: $117^{\circ}$ ) from the other ring atoms. The six-membered ring is not a perfect hexagon. The $\mathrm{O}-\mathrm{N}, \mathrm{N}-\mathrm{B}$, and $\mathrm{B}-\mathrm{O}$ bonds are slightly different lengths $(1.427,1.398$, and $1.378 \AA$, respectively), while the bond angles vary, sometimes significantly, from $120^{\circ}$. The relative orientations of the $\mathrm{NO}_{2}$ groups in tetranitro-NOB-NOB show an interesting pattern: the $\mathrm{NO}_{2}$ group bonded to the nitrogen atom in the ring lies in the plane of the ring, while the $\mathrm{NO}_{2}$ group

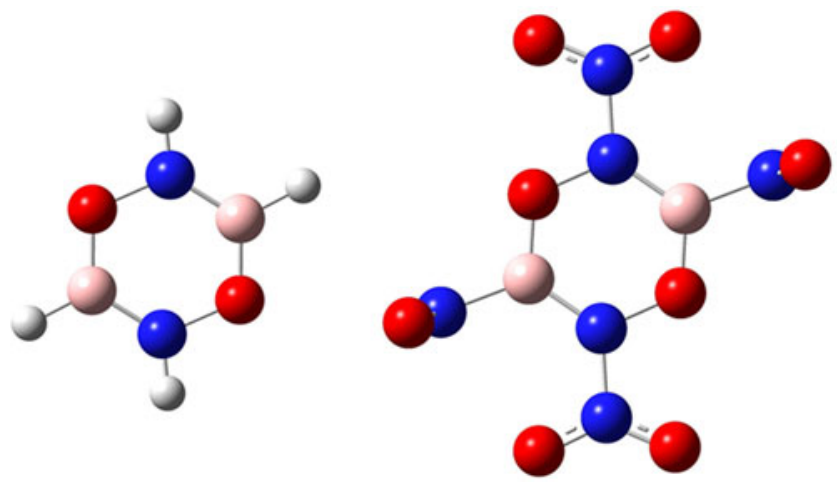

Fig. 2 The parent NOB-NOB molecule (cf. Fig. 1) and the tetranitroNOB-NOB molecule 
Table 1 Representative bonding parameters of the parent NOB-NOB molecule and the tetranitro-NOB-NOB derivative. Distances in $\AA$, angles in degrees

\begin{tabular}{lll}
\hline & NOB-NOB & Tetranitro-NOB-NOB \\
\hline$r(\mathrm{~N}-\mathrm{O})$ & 1.427 & 1.399 \\
$r(\mathrm{O}-\mathrm{B})$ & 1.378 & 1.363 \\
$r(\mathrm{~B}-\mathrm{N})$ & 1.398 & 1.419 \\
$r(\mathrm{~N}-\mathrm{H})$ & 1.006 & - \\
$r(\mathrm{~B}-\mathrm{H})$ & 1.189 & - \\
$r(\mathrm{~N}-\mathrm{N})$ & - & 1.443 \\
$r(\mathrm{~B}-\mathrm{NO})$ & - & 1.516 \\
$\alpha(\mathrm{B}-\mathrm{O}-\mathrm{N})$ & 113.9 & 117.3 \\
$\alpha(\mathrm{O}-\mathrm{N}-\mathrm{B})$ & 124.1 & 121.7 \\
$\alpha(\mathrm{N}-\mathrm{B}-\mathrm{O})$ & 122 & 121.1 \\
$\alpha(\mathrm{O}-\mathrm{B}-\mathrm{H})$ & 117.8 & - \\
$\alpha(\mathrm{O}-\mathrm{N}-\mathrm{H})$ & 108.3 & - \\
$\alpha(\mathrm{O}-\mathrm{N}-\mathrm{O})$ & - & $127.0,130.6$ \\
\hline
\end{tabular}

bonded to the boron atom in the ring lies perpendicular to the ring. This pattern is repeated in all NOB-NOB derivatives that have $\mathrm{NO}_{2}$ groups on adjacent atoms (which is seen for three derivatives in the group of ten molecules studied here): the $\mathrm{NO}_{2}$ group bonded to the nitrogen atom is always in the plane of the ring, while the $\mathrm{NO}_{2}$ group bonded to the boron atom is always perpendicular to the plane of the ring. This is unusual for an ortho-substituted di- (or greater) nitro compound with a planar central ring. For example, 1,2-dinitrobenzene has its adjacent nitro groups rotated $\sim 41^{\circ}$ out of the plane of the planar $\mathrm{C}_{6}$ ring [8], while the nitro groups in hexanitrobenzene are all 43$45^{\circ}$ out of the plane of the ring [9].

The general structure of the BON-BON molecules studied previously (Lawong AK, Ball DW, 2011, manuscript in preparation) included a central six-membered ring that resembled the chair conformation of cyclohexane. The first major difference in the structures of BON-BON and NOB-NOB (in both cases referring to the parent molecule) is a nonplanar chair conformation for BON-BON and a flat, distorted hexagon for NOB-NOB. As for bond distances within the six-membered rings, only the $\mathrm{N}-\mathrm{O}$ bond distance remains close to being the same for the two types of rings $(1.427 \AA$ here versus $1.429 \AA$ for the parent BON-BON molecule). The $\mathrm{B}-\mathrm{O}$ bond is slightly shorter in NOB-NOB $(1.378 \AA$ here versus $1.476 \AA$ in BON-BON). The B-N bond is significantly shorter in NOB-NOB $(1.427 \AA$ vs. $1.624 \AA$ ), as might be expected for a B atom bonding to a trivalent $\mathrm{N}$ atom. Bonding to and bonding within the $\mathrm{NO}_{2}$ groups were similar in the two types of molecules, except for the N-N(nitro) bond; again, as befitting a bond to a trivalent $\mathrm{N}$ atom, the $\mathrm{N}-\mathrm{N}$ bond distance in tetranitro-NOBNOB was found to be $1.443 \AA$, down significantly from the
1.696-1.899 $\AA$ bond distance found in octanitro-BONBON (Lawong AK, Ball DW, 2011, manuscript in preparation).

A look at some of the molecular orbitals explains why the six-membered rings of NOB-NOB are close to being planar. Figure 3 shows HOMO-7 and HOMO-21 for the parent NOB-NOB and the tetranitro derivative, respectively. These molecular orbitals show the delocalization of electrons over the entire ring and even, in the case of the tetranitro derivative, into the $\mathrm{NO}_{2}$ groups. This is very reminiscent of the $\pi$ orbitals of aromatic systems, and it would not be surprising if this molecule were found to have aromatic character.

Figure 4 shows the calculated vibrational spectra of the parent NOB-NOB molecule and the tetranitro derivative, which should help in identifying these substances should synthesis be attempted. The vibrational spectrum of NOBNOB is unremarkable, with the $\mathrm{N}-\mathrm{H}, \mathrm{B}-\mathrm{H}$, and ring vibrations appearing in predictable ranges. The vibrational spectrum of tetranitro-NOB-NOB is more interesting. Some features that stand out are what appear to be doublets of absorptions throughout the spectrum, especially in the midto high-energy range. Visualization of the normal vibrational modes using the GaussView program [10] demonstrates the reason for these near-doublets. Each pair represents two similar motions that would otherwise be degenerate if the symmetry of the molecule were higher. For example, the strong absorption at $1765 \mathrm{~cm}^{-1}$ is the asymmetric $\mathrm{O}-\mathrm{N}-\mathrm{O}$ stretch of the two $\mathrm{NO}_{2}$ groups bonded to the nitrogen atoms in the ring. The strong absorption near it, at $1629 \mathrm{~cm}^{-1}$, is the asymmetric $\mathrm{O}-\mathrm{N}-\mathrm{O}$ stretch of the two $\mathrm{NO}_{2}$ groups bonded to the boron atoms in the ring. Within $2 \mathrm{~cm}^{-1}$ of each of these strong absorptions is a zerointensity absorption identifiable as the corresponding symmetric stretches of the same atoms. Similar correspondences can be assigned to other absorptions of similar intensities and close frequencies. Also, because of the symmetry of the molecule, fully 25 of the 48 normal modes of vibration have exactly zero intensity (compared to only 10 out of 24 for the parent NOB-NOB molecule).
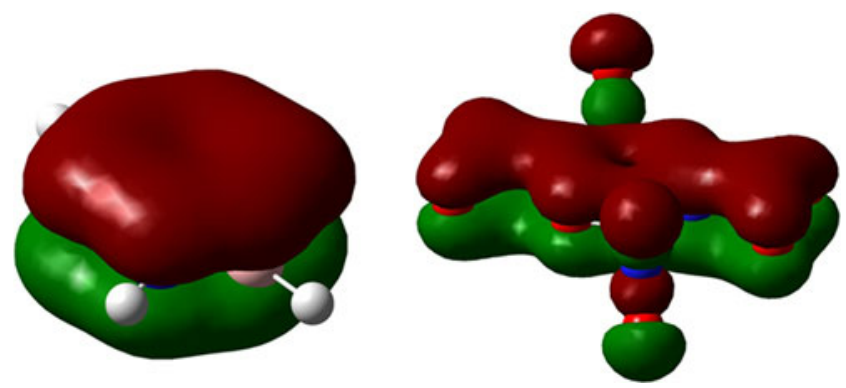

Fig. 3 Molecular orbitals showing the delocalization of electrons in the ring (left, parent NOB-NOB) and extending into the $\mathrm{NO}_{2}$ groups planar to the ring (right, tetranitro-NOB-NOB) 
Because our main focus is the thermodynamics of the NOB-NOB molecules, here we will include information about all of the isomers. After determining the enthalpy of formation of the molecules as described above, the combustion or decomposition enthalpy was also determined. Whether the relevant reaction is considered a combustion or decomposition depends on the oxygen balance $(\mathrm{OB} \%)$ of the compound. The oxygen balance is given by the expression [11]

$\mathrm{OB} \%=-\frac{3200\left(\frac{3}{4} b+\frac{1}{4} h+0 n-\frac{1}{2} o\right)}{\mathrm{MW}}$,

where $b, h, n$, and $o$ are the numbers of boron, hydrogen, nitrogen, and oxygen atoms in the molecular formulae, respectively, and MW is the molar mass of the molecule. An $\mathrm{OB} \%$ that is less than zero indicates that a molecular formula does not have sufficient oxidizer (here, oxygen) present to oxidize all other atoms present, while an $\mathrm{OB} \%$ of greater than zero indicates that a molecular formula does contain sufficient oxidizer to oxidize all other atoms fully. Thus, substances with negative OB\% values need additional oxidizer (assumed here to be molecular oxygen), and the enthalpy changes of reaction with said oxidizer are appropriately labeled enthalpies of combustion $\left(\Delta H_{\text {comb }}\right)$. Substances with positive OB\% values have sufficient oxidizer atoms to oxidize themselves, so the enthalpy changes of reaction are more appropriately labeled enthalpies of decomposition $\left(\Delta H_{\mathrm{dec}}\right)$. Table 2 lists oxygen balances, calculated enthalpies of formation, and resulting enthalpies of decomposition or combustion for the ten NOB-NOB derivatives. There are considerably fewer nitroNOB-NOB molecules than nitro-BON-BON molecules because of the fewer hydrogen atoms that can be substituted for $\mathrm{NO}_{2}$ groups, which in turn leads to fewer substitutional isomers. In the labeling of the nitro-NOBNOB isomers, the point of substitution is given, with the prime (') implying that the additional $\mathrm{NO}_{2}$ substitution (where appropriate) is in the other NOB monomer as well. According to the OB\% values, the parent NOB-NOB and nitro-NOB-NOB require extra oxidizer, so the enthalpies of reaction are enthalpies of combustion. For greater $\mathrm{NO}_{2}$ substitution, the positive $\mathrm{OB} \%$ values indicate sufficient oxygen to oxidize completely, so enthalpies are better described as decomposition enthalpies.

Table 2 shows that all of the NOB-NOB-based compounds have strongly negative enthalpies of formation, likely due in part to the strong $\mathrm{B}-\mathrm{N}$ bonds in the sixmembered rings. Upon nitration, the thermodynamics of the isomers shows a similar trend to the respective BON-BON compounds, but not as extreme. Once again, in the nitrosubstituted compound, the site of nitration significantly affects the energy values, with the B-substituted nitro-NOB-
Fig. 4 Calculated vibrational spectra of the parent NOB-NOB molecule (bottom) and the tetranitro derivative (top). Note that the horizontal scales are different for the two spectra

NOB predicted to be more stable than the N-substituted nitro-NOB-NOB. However, the difference in $\Delta H_{\mathrm{f}}$ values is only about $120 \mathrm{~kJ} \mathrm{~mol}^{-1}$, rather than the $220 \mathrm{~kJ} \mathrm{~mol}^{-1}$ seen between the two nitro-BON-BON derivatives. The trend is clear in the NOB-NOB derivatives, as it was in the BONBON molecules: all other things being the same, an $\mathrm{NO}_{2}$ group bonded to an $\mathrm{N}$ atom of the six-membered ring leads to a less-stable isomer than a similar molecule with the $\mathrm{NO}_{2}$ group bonded to a B atom of the ring.

The calculated enthalpies of formation generally increase (that is, get less negative) as the level of nitration increases; however, the increase is not monotonic. The least stable isomer, relative to the constituent elements, is $\mathrm{N} \mathrm{N}^{\prime}$-dinitroNOB-NOB. In this molecule, both of the relatively stable $\mathrm{N}-\mathrm{H}$ bonds from the parent compound are substituted for $\mathrm{NO}_{2}$ groups, so they are replaced with less-stable $\mathrm{N}-\mathrm{NO}_{2}$ bonds. As mentioned in the BON-BON paper (Lawong AK, Ball DW, 2011, manuscript in preparation), these $\mathrm{N}-\mathrm{N}$ bonds are the most likely to initiate decomposition in this case too.

With enthalpies of formation determined, enthalpies of combustion or decomposition can be determined using standard combustion or decomposition reactions. The enthalpy of combustion of the parent NOB-NOB molecule is $-957 \mathrm{~kJ} \mathrm{~mol}^{-1}$. Per unit mass, this molar enthalpy of combustion is recalculated to a value of $-11.2 \mathrm{~kJ} \mathrm{~g}^{-1}$. This is about twice as much energy per unit mass as current HE materials like RDX and HMS, whose specific enthalpies of decomposition are both about $5 \mathrm{~kJ} \mathrm{~g}^{-1}$ [12]. However, this is significantly lower than the specific enthalpy of combustion for the parent BON-BON compound, which is $-16.6 \mathrm{~kJ} \mathrm{~g}^{-1}$. With four less hydrogen atoms and stronger $\mathrm{B}-\mathrm{N}$ bonds, the parent NOB-NOB compound not only has a more negative enthalpy of formation than the parent BON-BON, but it gives off two less $\mathrm{H}_{2} \mathrm{O}$ molecules as combustion products. The enthalpies of combustion of the two nitro-NOB-NOB isomers are slightly less negative than that of the parent molecule, and because of the rather dramatic increase in mass brought on by a single $\mathrm{NO}_{2}$ group (89.6 u for the parent molecule, but $134.6 \mathrm{u}$ for nitroNOB-NOB: a $50.4 \%$ increase), the energy given off per gram decreases by about half, to -5.9 to $-6.9 \mathrm{~kJ} \mathrm{~g}^{-1}$. Upon increasing the nitro content, the calculated enthalpies of decomposition vary between -570 and $-855 \mathrm{~kJ} \mathrm{~mol}^{-1}$, varying more because of the position of the $\mathrm{NO}_{2}$ group rather than the number of $\mathrm{NO}_{2}$ groups. This is in part because higher levels of nitration lead to the formation of more $\mathrm{N}_{2}$ and $\mathrm{O}_{2}$ as products, which have enthalpies of formation of zero and thus contribute nothing to the 

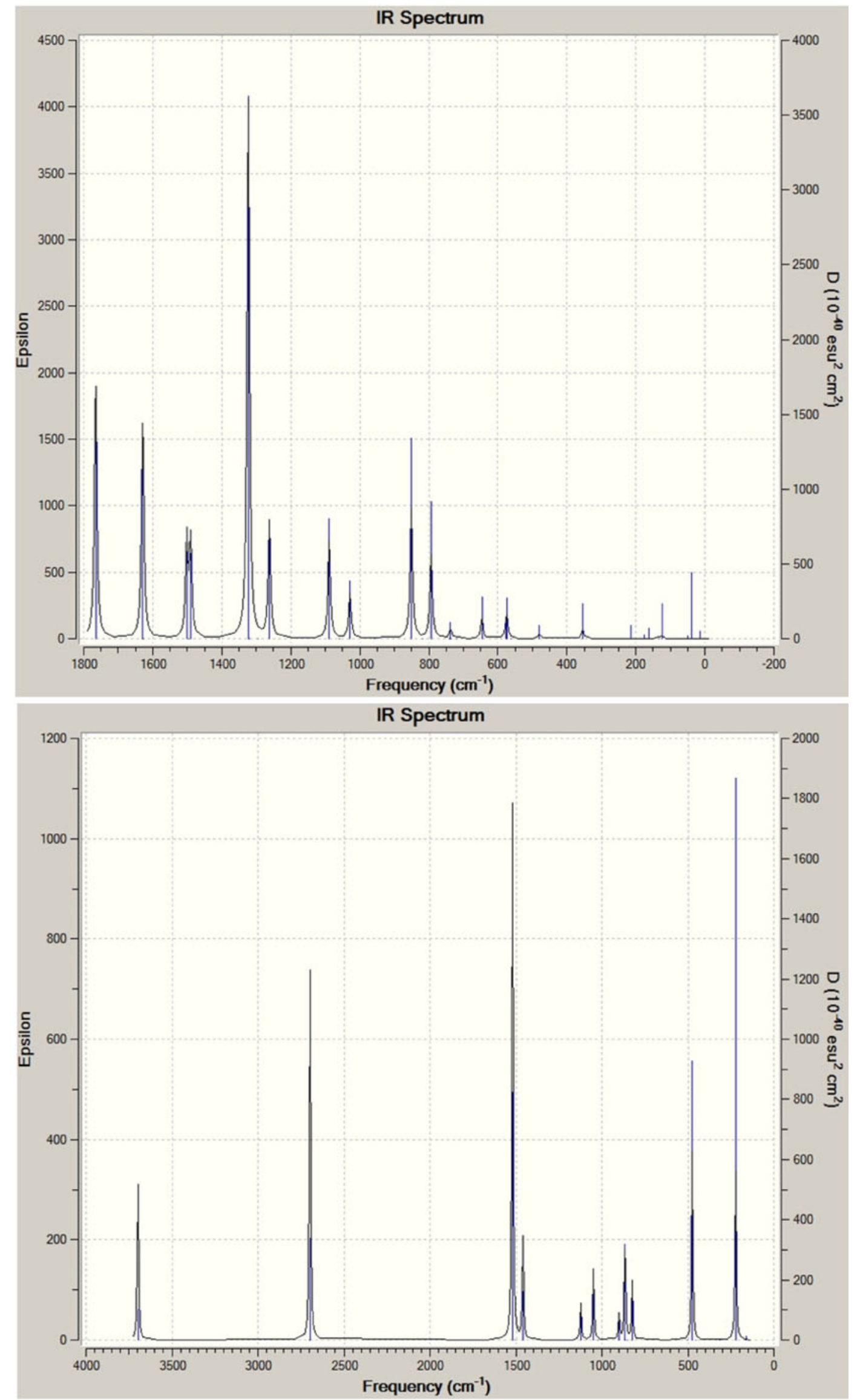
Table 2 Oxygen balances, enthalpies of formation and combustion/decomposition, and specific enthalpies of reaction for NOB-NOB and its nitrated derivatives

\begin{tabular}{lllll}
\hline Molecule & $\mathrm{OB} \%$ & $\Delta H_{\mathrm{f}}\left(\mathrm{kJ} \mathrm{mol}^{-1}\right)$ & $\Delta H_{\mathrm{comb} / \mathrm{dec}}\left(\mathrm{kJ} \mathrm{mol}^{-1}\right)$ & $\Delta H_{\mathrm{comb} / \mathrm{dec}}\left(\mathrm{kJ} \mathrm{g}^{-1}\right)$ \\
\hline NHOBH-NHOBH & -56.1 & -362.7 & -957 & -11.2 \\
Nitro-NOB-NOB & -6.1 & & & \\
B- & & -426.7 & -772 & -5.91 \\
N- & & -300.9 & -897.8 & -6.87 \\
Dinitro-NOB-NOB & 18.2 & & & \\
B,B'- & & -478.3 & -599.5 & -3.41 \\
B,N- & & -349.1 & -728.7 & -4.15 \\
B,N'- & & -334.9 & -742.9 & -4.23 \\
N,N'- & & -222.6 & -855.2 & -4.87 \\
Trinitro-NOB-NOB & 32.6 & & & -2.64 \\
B,N,B'- & & -375.2 & -581.7 & -3.22 \\
B,N,N'- & & -246.4 & -710.5 & -2.23 \\
Tetranitro-NOB-NOB & 43.6 & -264.24 & -571.7 & \\
\end{tabular}

generation of stable products. The fact that one-half of an $\mathrm{H}_{2} \mathrm{O}$ molecule less is formed as a product with the addition of each $\mathrm{NO}_{2}$ group apparently has only minimal impact on the resulting enthalpy of decomposition.

However, although the enthalpies of decomposition are fluctuating about a mean (which is about $-680 \mathrm{~kJ} \mathrm{~mol}^{-1}$ ), the mass of the molecule is increasing by a net $45.0 \mathrm{u}$ per nitro group, so the enthalpies of decomposition per unit gram are decreasing noticeably. The specific enthalpies of formation for all dinitro-NOB-NOB isomers are less than those for nitro-NOB-NOB, and trinitro-NOB-NOB isomers even lower. The tetranitro-NOB-NOB derivative has the lowest specific enthalpy of decomposition, $-2.23 \mathrm{~kJ} \mathrm{~mol}^{-1}$. Even this value is not entirely out of range for potential HE materials; Akhavan lists [12] the specific enthalpy of reaction for nitroguanidine at $-2.47 \mathrm{~kJ} \mathrm{~g}^{-1}$, just slightly more energy per gram than that of tetranitro-NOB-NOB.

We point out that even this lowest value for tetranitroNOB-NOB is more energy than six types of nitrated BONBON molecules (Lawong AK, Ball DW, 2011, manuscript in preparation), which can accommodate more $\mathrm{NO}_{2}$ groups and hence achieve higher molar masses, reducing their energy density despite their more negative enthalpies of decomposition. Thus, nitrated NOB-NOB derivatives may be potential $\mathrm{HE}$ candidates that are worthy of additional exploration. Other factors need to be considered before nitrated NOB-NOB molecules would be deemed "good" HE materials, like velocity of detonation and impact sensitivity. However, for at least some NOB-NOB compounds, their thermodynamics of combustion and decomposition are promising.

Acknowledgments We would like to thank the Ohio Supercomputer Center in Columbus, $\mathrm{OH}$, for granting us time to perform this work. AKL thanks the McNair Scholars Program at Cleveland State University for support.

\section{References}

1. Kuhn LP, Inatome N (1963) J Am Chem Soc 85:1206-1207

2. Thomson HB, Kuhn LP, Inatome N (1964) J Phys Chem 68:421422

3. Frisch MJ, Trucks GW, Schlegel HB et al (2009) Gaussian 09, revision A.01. Gaussian, Inc., Wallingford

4. Becke AD (1993) J Chem Phys 98:5648-5652

5. Lee C, Yang W, Parr RG (1988) Phys Rev 37:785-789

6. Hariharan PC, Pople JA (1973) Theor Chem Acc 28:213-222

7. National Institute of Standards and Technology (2011) NIST chemistry webbook. http://webbook.nist.gov. Accessed April 28, 2011

8. Herbstein FH, Kapon M (1990) Acta Cryst B46:567-572

9. Akopyan ZA, Struchkov YT, Dashevskii VG (2006) J Struct Chem 7:385-392

10. Dennington R, Keith T, Millam J (2007) GaussView, version 4.1. Semichem Inc., Shawnee Mission

11. Persson PA, Holmberg R, Lee J (1993) Rock blasting and explosives engineering. CRC Press, Boca Raton

12. Akhavan J (2004) The chemistry of explosives, 2nd edn. Royal Society of Chemistry, London 